\title{
Cartilage Matrix Glycoprotein Is Present in Serum in Experimental Canine Osteoarthritis
}

Rose S. Fife ${ }^{\star \ddagger}$ and Kenneth D. Brandt*

${ }^{*}$ Rheumatology Division, Department of Medicine, and ${ }^{\ddagger}$ Department of Biochemistry, Indiana University School of Medicine, Indianapolis, Indiana 46202

\begin{abstract}
We have described previously a disulfide-bonded 550,000-D cartilage matrix glycoprotein (CMGP), which is found in normal hyaline cartilage, fibrocartilage, and the vitreous of the eye, and consists of subunits with apparent molecular weights of 130,000 in $4 \%$ gels $(116,000$ in $9 \%$ gels). In osteoarthritic cartilage from dogs subjected to transection of the anterior cruciate ligament (ACL), CMGP is cleaved to major immunoreactive fragments with apparent molecular weights of 65,000 and 75,000 after reduction with 2-mercaptoethanol. In the present study, using immunolocation analysis, a monoclonal antibody to CMGP did not react with serum from 8 of 12 dogs before ACL transection but did react with serum from seven of these animals 4 wk after surgery and with serum from 10 dogs at sacrifice, 8-14 wk after ACL transection. Serum from four dogs reacted with the monoclonal antibody before ACL transection. Serum from two dogs was negative at all time points. Immunolocation studies using a polyclonal antiserum to CMGP were performed in seven of these dogs and produced results identical with the monoclonal antibody in four dogs. In contrast, analysis of serial serum samples from three dogs with cartilage atrophy revealed no evidence of CMGP at any time point. These data suggest that CMGP may be a serum marker for osteoarthritis in this canine model.
\end{abstract}

\section{Introduction}

We have previously described a 550,000-D noncollagenous, nonproteoglycan cartilage matrix glycoprotein (CMGP), ${ }^{1}$ which consists of disulfide-bonded subunits with apparent molecular weights of 130,000 each in 4\% SDS-polyacrylamide gels $(116,000$ in $9 \%$ gels) $(1,2)$. CMGP is found in normal hyaline cartilage (1) and fibrocartilage (2) and in the vitreous of the eye (3). It has not been detected in normal human or canine serum or in normal human synovial fluid (1), but it is found in synovial fluid from patients with osteoarthritis (4). CMGP represents $\sim 10 \%$ of the total newly synthesized noncollagenous, nonproteoglycan protein in organ cultures of

Address reprint requests to Dr. Fife, Rheumatology Division, Indiana University School of Medicine, 541 Clinical Drive, Indianapolis, IN 46202. 1989.

Received for publication 10 April 1987 and in revised form 19 July

1. Abbreviations used in this paper: $\mathrm{ACL}$, anterior cruciate ligament; CMGP, cartilage matrix glycoprotein.

J. Clin. Invest.

(c) The American Society for Clinical Investigation, Inc. $0021-9738 / 89 / 10 / 1432 / 08 \$ 2.00$

Volume 84, November 1989, 1432-1439 normal canine articular cartilage (5). It is rapidly metabolized in short-term organ cultures of canine articular cartilage, where it has a half-life of 48-72 h (5). Immunofluorescence studies have revealed that CMGP is located in a pericellular and interterritorial distribution in normal adult canine articular cartilage (6).

We have examined this protein in cartilage from dogs with osteoarthritis produced by transection of the ipsilateral anterior cruciate ligament (ACL) (7). In extracts of the osteoarthritic cartilage, most of the immunoreactivity appeared as a major fragment with an apparent molecular weight of 65,000 and as a less intense fragment with an apparent molecular weight of 75,000 after reduction with 2-mercaptoethanol (7). Significantly less $116,000-D$ subunit protein was noted in $9 \%$ gels after reduction of extracts of the osteoarthritic cartilage than in extracts of cartilage from the contralateral knees or of normal control canine cartilage (7). The purpose of the present study was to determine whether CMGP might serve as a serum marker for osteoarthritis in this model.

\section{Methods}

Osteoarthritis model. 12 normal adult mongrel dogs underwent transection of the right ACL through a sterile incision using a standard surgical procedure employed in this laboratory $(8,9)$. Briefly, the joint capsule was entered via an oblique anteromedial approach. The ACL was transected with a scalpel, and the cartilage was not damaged (8). After suturing, the animals were allowed to ambulate in their pens until they were killed with an overdose of sodium pentothal 8-14 wk postoperatively. Serum was obtained from each dog before surgery, 4 wk postoperatively, and at sacrifice, 8-14 wk after surgery, and was stored at $-20^{\circ} \mathrm{C}$ until used.

Cartilage atrophy model. One hind limb of three normal adult mongrel dogs was immobilized for $8 \mathrm{wk}$ in an orthopedic cast in $\sim 90^{\circ}$ of hip and knee flexion without forced compression (10). Serum was obtained from each dog before casting, 4 wk later, and at death after 8 wk of immobilization, and was stored at $-20^{\circ} \mathrm{C}$ until used.

Gel electrophoresis and immunolocation analysis. Aliquots of all serum samples were treated with $1 \%$ (vol/vol) 2-mercaptoethanol (Bio-Rad Laboratories, Richmond, CA) before electrophoresis. Electrophoresis was performed in $4 \%$ and $9 \%$ SDS-polyacrylamide slab gels in a Laemmli system (11). The gels were transferred to nitrocellulose membranes (Millipore Corp., Bedford, MA) in an E-C Electro-Blot apparatus (E-C Apparatus Corp., St. Petersburg, FL), as described elsewhere $(12,13)$ or with a Deca-Probe (Hoefer Scientific Instruments, San Francisco, CA). Non-fat dry milk (Carnation, Los Angeles, CA) was used as a $0.5 \%$ solution to prevent nonspecific protein binding by the nitrocellulose membranes (14). The membranes were cut into strips and were incubated with a mouse monoclonal antibody to CMGP (see below), with a specific rabbit polyclonal antiserum to CMGP $(1,2,6)$, or with nonimmune control serum, and then with ${ }^{125}$ I-labeled goat anti-mouse immunoglobulin antiserum for the mouse antibody (New England Nuclear, Boston, MA) or with ${ }^{125}$ I-labeled staphylococcal protein A for the rabbit antiserum (New England Nuclear) before autoradiography $(1,12,13)$. The monoclonal antibody was used to examine all serum samples from the osteoarthritic dogs, 
while only seven of these sets of samples were available for study with the polyclonal antiserum (Table I). The samples from the casted animals were examined only with the polyclonal antiserum.

Production of monoclonal antibody. A monoclonal antibody has been prepared to bovine CMGP in the Hybridoma Core Facility of the Indiana University Diabetes Research and Training Center (Dr. Merrill D. Benson, Director) by Mr. W. Kuster. Normal cartilage was obtained from the hock joints of adult steers (2-3 yr of age) at the time of slaughter. The cartilage was pooled and frozen at $-70^{\circ} \mathrm{C}$ until used. The cartilage was finely ground in liquid nitrogen, using a mortar and pestle, and was extracted for $48 \mathrm{~h}$ at $4^{\circ} \mathrm{C}$ with $0.15 \mathrm{M} \mathrm{NaCl}$, buffered with $0.05 \mathrm{M}$ sodium acetate, $\mathrm{pH} 5.8$, containing $0.01 \mathrm{M} \mathrm{N}$-ethylmaleimide (Sigma Chemical Co., St. Louis, MO), and protease inhibitors, as described elsewhere $(1,2,6,15,16)$. After extraction, the samples were centrifuged at $18,000 \mathrm{~g}$ for $30 \mathrm{~min}$ at $4^{\circ} \mathrm{C}$ in a Beckman J-21B centrifuge (Beckman Instruments Inc., Palo Alto, CA). The supernatant was filtered and dialyzed against $0.05 \mathrm{M}$ sodium acetate, $\mathrm{pH} 7.2$, in the presence of the protease inhibitors.

We have described previously the production of a rabbit antiserum to bovine CMGP $(1,6)$. This antiserum was precipitated with saturated ammonium sulfate and was coupled to AH-Sepharose-4B beads (Pharmacia Fine Chemicals, Piscataway, NJ), using a carbodiimide linkage, per the manufacturer's instructions. The bovine cartilage extract, which had been dialyzed against $0.05 \mathrm{M}$ sodium acetate, was diluted 1:10 with PBS, containing $0.25 \%$ deoxycholate and $0.25 \%$ Nonidet P-40 (LKB, Bromma, Sweden) (17). $1 \mathrm{ml}$ was layered onto a 3-ml affinity column for $1 \mathrm{~h}$. The column was washed with two column-volumes of PBS and one column-volume of $3 \mathrm{M}$ magnesium chloride (17). The fractions were monitored at $206 \mathrm{~nm}$ on a spectrophotometer (260; Gilford Instruments Inc., Oberlin, OH). Portions of the protein-rich fractions that eluted with $3 \mathrm{M}$ magnesium chloride were dialyzed against SDS-containing sample buffer (see above). Aliquots were electrophoresed in $9 \%$ SDS-polyacrylamide gels, as described above, and were stained with Coomassie blue or were studied by immunolocation analysis after transfer to nitrocellulose membranes to identify fractions containing purified CMGP.

To produce the monoclonal antibody, 12-wk-old BALB/c female mice were immunized intraperitoneally with $100 \mu \mathrm{g}$ of affinity column-purified CMGP in complete Freund's adjuvant. The mice were boosted intraperitoneally with $50 \mu \mathrm{g}$ of CMGP in incomplete Freund's adjuvant every $2 \mathrm{wk}$. When polyclonal antibodies to CMGP were demonstrable by double diffusion in agar, the mice were boosted intraperitoneally with $20 \mu \mathrm{g}$ of CMGP in saline. They were killed $4 \mathrm{~d}$ later, and spleen cells were fused to the murine myeloma cell line P3XAg8.653 (18) at a ratio of 5 spleen cells to one myeloma cell in $50 \%$ polyethylene glycol, according to the method of Kohler and Milstein (19).

Hybridomas were screened for production of antibody to CMGP. CMGP was bound to 96-well ELISA plates (Dynatech, Alexandria, VA) coated overnight with $100 \mu \mathrm{l}$ of a $10 \mu \mathrm{g} / \mathrm{ml}$ solution of purified bovine CMGP in $0.05 \mathrm{M}$ carbonate buffer, $\mathrm{pH} 9.6(20-22)$. The plates were decanted and nonspecific protein binding was blocked with $0.5 \%$ BSA in PBS, pH 7.4, for $2 \mathrm{~h}$ at $37^{\circ} \mathrm{C} .100 \mu \mathrm{l}$ of hybridoma supernatant was added, and the samples were incubated for $2 \mathrm{~h}$ at $37^{\circ} \mathrm{C}$. The plates were washed and bound antibody was detected using goat anti-mouse immunoglobulin antiserum conjugated to alkaline phosphatase (Sigma) in a $1: 1,000$ dilution for $1 \mathrm{~h}$ at $37^{\circ} \mathrm{C}$. The plates were then incubated with $1 \mathrm{mg} / \mathrm{ml}$ of $p$-nitrophenylphosphate (Sigma) in $10 \%$ diethanolamine buffer, pH $9.8(20-22)$. Absorbance was read at 400 $\mathrm{nm}$ in a Dynatech MR 600 micro-ELISA reader. Specific screening of selected clones was accomplished by immunolocation analysis of CMGP from extracts of bovine and canine cartilage on nitrocellulose membranes, as described above, using ${ }^{125}$ I-labeled goat anti-mouse immunoglobulin antiserum (New England Nuclear) as the second antibody. Control immunolocations were performed using type II collagen, proteoglycan, and link proteins as antigens.

One clone produced antibodies to the 116,000-D subunit of CMGP (ARS 5-G-3) and was used in this study. This antibody did not crossreact by immunolocation analysis on nitrocellulose membranes with type II collagen, proteoglycan, or link proteins. It did, however, crossreact with CMGP from normal canine cartilage and with fragments of CMGP with apparent molecular weights of 65,000 and 75,000 from extracts of bovine and canine cartilage. The clone was injected into the peritoneum of a mouse, and the resulting ascitic fluid was precipitated with saturated ammonium sulfate.

Histologic and biochemical studies. After death, full-thickness cartilage biopsies were obtained from two adjacent sites on the central weight-bearing surfaces of the medial femoral condyles of both knees of each dog. Portions of one biopsy from each dog were sectioned (6 $\mu \mathrm{m})$ and stained with Safranin-O-Fast green (23). The other piece was analyzed for uronic acid concentration $(24,25)$ and water content $(8)$. The $P$ values were determined by the paired $t$ test method. The thick-

Table I. Features of Osteoarthritis and Presence of CMGP in Serum of Dogs after Transection of Anterior Cruciate Ligament

\begin{tabular}{|c|c|c|c|c|c|c|c|c|c|c|c|c|c|c|}
\hline \multirow{3}{*}{$\begin{array}{l}\text { Dog } \\
\text { No. }\end{array}$} & \multicolumn{3}{|c|}{ Evidence of osteoarthritis } & \multirow{2}{*}{\multicolumn{2}{|c|}{$\begin{array}{l}\text { Uronic acid (\% } \\
\text { dry weight) }\end{array}$}} & \multirow{2}{*}{\multicolumn{2}{|c|}{$\begin{array}{l}\text { Water (\% total } \\
\text { weight) }\end{array}$}} & \multicolumn{6}{|c|}{ Serum CMGP, weeks after ACLT* } & \multirow{3}{*}{$\begin{array}{c}\text { Glycosaminoglycan } \\
\text { synthesis } \\
\text { (\% control) }\end{array}$} \\
\hline & \multirow{2}{*}{$\begin{array}{l}\text { Fraying of } \\
\text { superficial } \\
\text { zone }\end{array}$} & \multirow{2}{*}{$\begin{array}{l}\text { Chondrocyte } \\
\text { cloning }\end{array}$} & \multirow{2}{*}{$\begin{array}{l}\text { Safranin-O } \\
\text { staining }\end{array}$} & & & & & \multicolumn{2}{|c|}{0} & \multicolumn{2}{|c|}{4} & \multicolumn{2}{|c|}{ Sacrifice } & \\
\hline & & & & $\mathrm{OA}^{\ddagger}$ & CK & OA & CK & $\mathbf{M}$ & $\mathbf{P}$ & $\mathbf{M}$ & $\mathbf{P}$ & $\mathbf{M}$ & $\mathbf{P}$ & \\
\hline 1 & Mild & Mild & Increased & 3.7 & 1.9 & 68.3 & 62.1 & - & - & - & - & + & + & 148 \\
\hline 2 & Mild & Mild & Increased & 5.3 & 3.6 & 71.0 & 58.9 & + & + & + & + & + & + & 65 \\
\hline 3 & Moderate & Marked & Decreased & 4.8 & 3.8 & 72.3 & 61.3 & - & - & + & + & + & + & 100 \\
\hline 4 & Mild & Mild & Increased & 5.4 & 3.7 & 71.0 & 60.4 & - & + & + & + & + & + & 101 \\
\hline 5 & Mild & Mild & Normal & 3.9 & 3.2 & 67.2 & 53.6 & + & - & + & - & + & + & 148 \\
\hline 6 & Mild & Moderate & Increased & \multicolumn{2}{|c|}{ N/A } & \multicolumn{2}{|c|}{ N/A } & + & - & + & - & + & + & N/A \\
\hline 7 & None & Moderate & Increased & 10.6 & 1.2 & 85.9 & 56.0 & - & - & - & - & + & + & 129 \\
\hline 8 & Mild & Moderate & Decreased & 2.9 & 3.2 & 62.0 & 62.0 & - & & + & & + & & N/A \\
\hline 9 & Mild & Mild & Decreased & 3.5 & 3.1 & 62.0 & 62.0 & - & & - & & - & & N/A \\
\hline 10 & Mild & Mild & Increased & 6.0 & 4.9 & 74.2 & 61.3 & - & & - & & + & & N/A \\
\hline 11 & Mild & Moderate & Increased & 4.1 & 4.3 & 65.2 & 61.8 & + & & + & & + & & 105 \\
\hline 12 & Mild & Marked & Increased & \multicolumn{2}{|c|}{ N/A } & \multicolumn{2}{|c|}{ N/A } & - & & - & & - & & N/A \\
\hline
\end{tabular}

* ACLT, anterior cruciate ligament transection; ${ }^{\ddagger} \mathrm{OA}$, osteoarthritic knee, CK, contralateral knee; $\mathrm{M}$, monoclonal antibody, $\mathrm{P}$, polyclonal antiserum; -, absent, + , present, N/A, not available. 

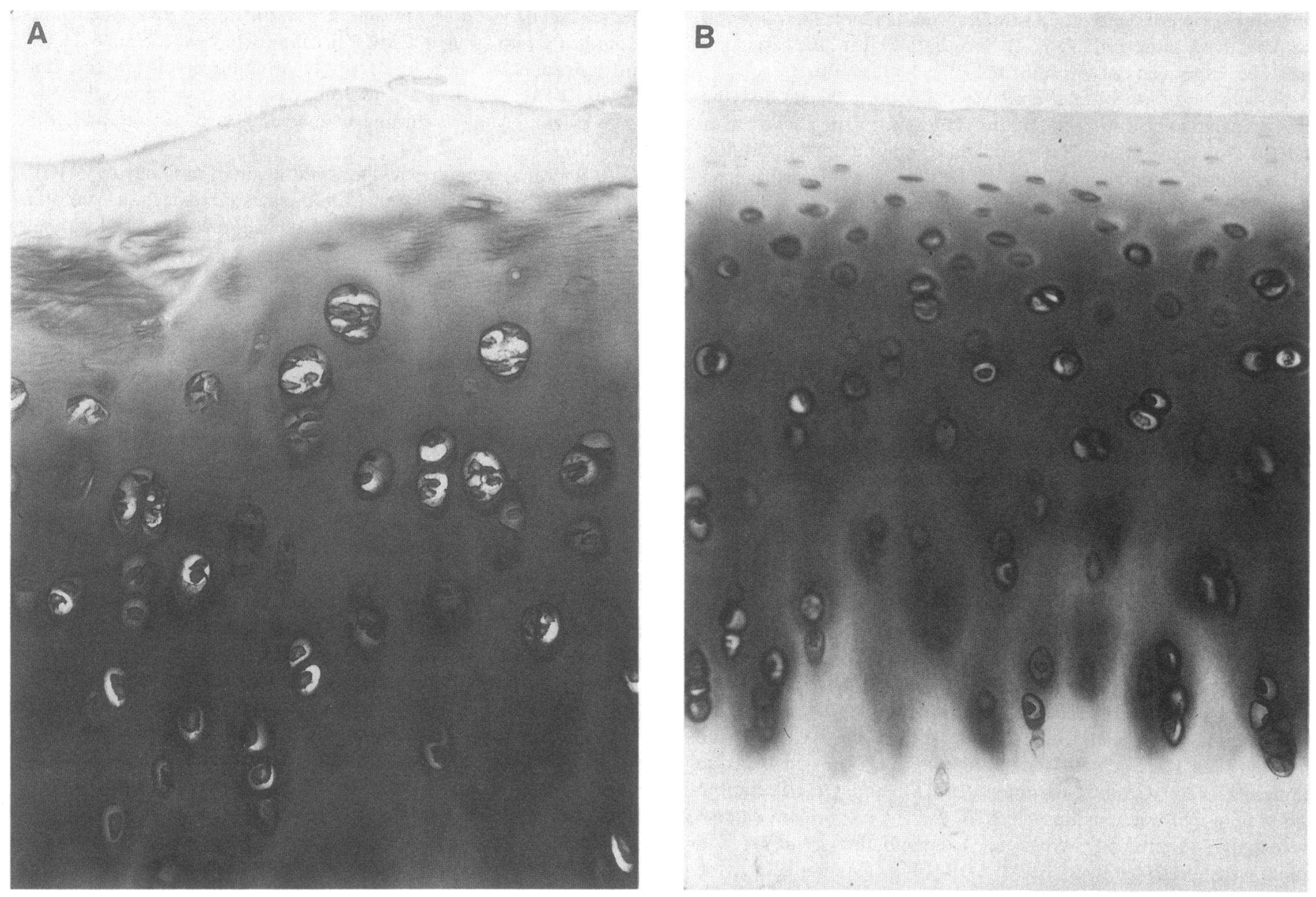

Figure 1. (A) Safranin-O-stained section of cartilage from knee of dog 3 which had been subjected to anterior cruciate ligament transection 8 wk earlier, showing changes of osteoarthritis with chondrocyte cloning and fraying. $(\times 250)$. $(B)$ Contralateral unoperated knee from same animal showing normal cartilage.

ness in millimeters of the samples from the casted dogs was measured with a micrometer from the cartilage surface to the tidemark. 10 measurements of each section were taken, and the results were averaged.

Glycosaminoglycan metabolism. Slices of cartilage from weightbearing areas of medial and lateral femoral condyles of both knees of seven of the dogs subjected to ACL transection and of all of the casted dogs were incubated in triplicate in Ham's F-12 culture medium containing $10 \%$ newborn calf serum for $20 \mathrm{~h}$ at $37^{\circ} \mathrm{C}$ in $95 \%$ air $/ 5 \% \mathrm{CO}_{2}$. This was followed by a 4-h incubation with medium containing ${ }^{35} \mathrm{~S}$-labeled sulfate $(20 \mu \mathrm{Ci} / \mathrm{ml})$ (New England Nuclear). At the end of the incubation period, the medium was removed and the cartilage was weighed and digested with $1 \mathrm{mg} / \mathrm{ml}$ of pronase (Calbiochem-Behring Diagnostics, La Jolla, CA). The medium and the pronase-digested cartilage were dialyzed to yield background counts in the dialysate, and net glycosaminoglycan synthesis was determined by the sum of the counts per minute in the medium and the pronase digest and was expressed as percent of that of the samples from the contralateral knee (26).

\section{Results}

Osteoarthritis model. Gross inspection of the operated knees revealed osteophytes and irregularity of the cartilage surface. The contralateral (unoperated) knees were normal. Sections of cartilage from the operated knees of all 12 dogs revealed changes compatible with mild to moderate osteoarthritis (Fig. $1 \mathrm{~A}$ ), with chondrocyte clones in all 12 dogs and fraying of the superficial zone in 11. Safranin-O staining was increased, primarily in the superficial regions, in eight dogs (Table I). Sections of cartilage from the contralateral knees were histologically and histochemically normal (Fig. $1 B$ ).

Uronic acid concentration and water content were determined on aliquots of cartilage from both knees of 10 of the dogs (Table I). The mean uronic acid concentration of cartilage from the osteoarthritic knees was $5.02 \pm 2.19 \%$ dry weight of cartilage, while that of the contralateral knees was $3.29 \pm 1.08 \%(P=0.082)$. The mean water content was $69.91 \pm 6.99 \%$ of the total weight of the osteoarthritic cartilage and $59.94 \pm 2.93 \%$ of the total weight of the samples from the contralateral knees $(P=0.006)$.

9\% SDS-polyacrylamide gels of serum samples obtained from 8 of the 12 dogs before ACL transection and reduced with 2-mercaptoethanol revealed no immunoreactive material when transferred to nitrocellulose membranes and incubated with the monoclonal antibody, followed by incubation with ${ }^{125}$ I-labeled goat anti-mouse immunoglobulin antiserum and autoradiography (Table I and Fig. 2). In contrast, serum from the other four dogs reacted with the monoclonal antibody before ACL transection (Table I). The apparent molecular weight of the immunoreactive material after reduction with 2-mercaptoethanol was 116,000 in $9 \%$ gels (corresponding to the $130,000-\mathrm{D}$ subunit of CMGP in $4 \%$ gels). Purified bovine 

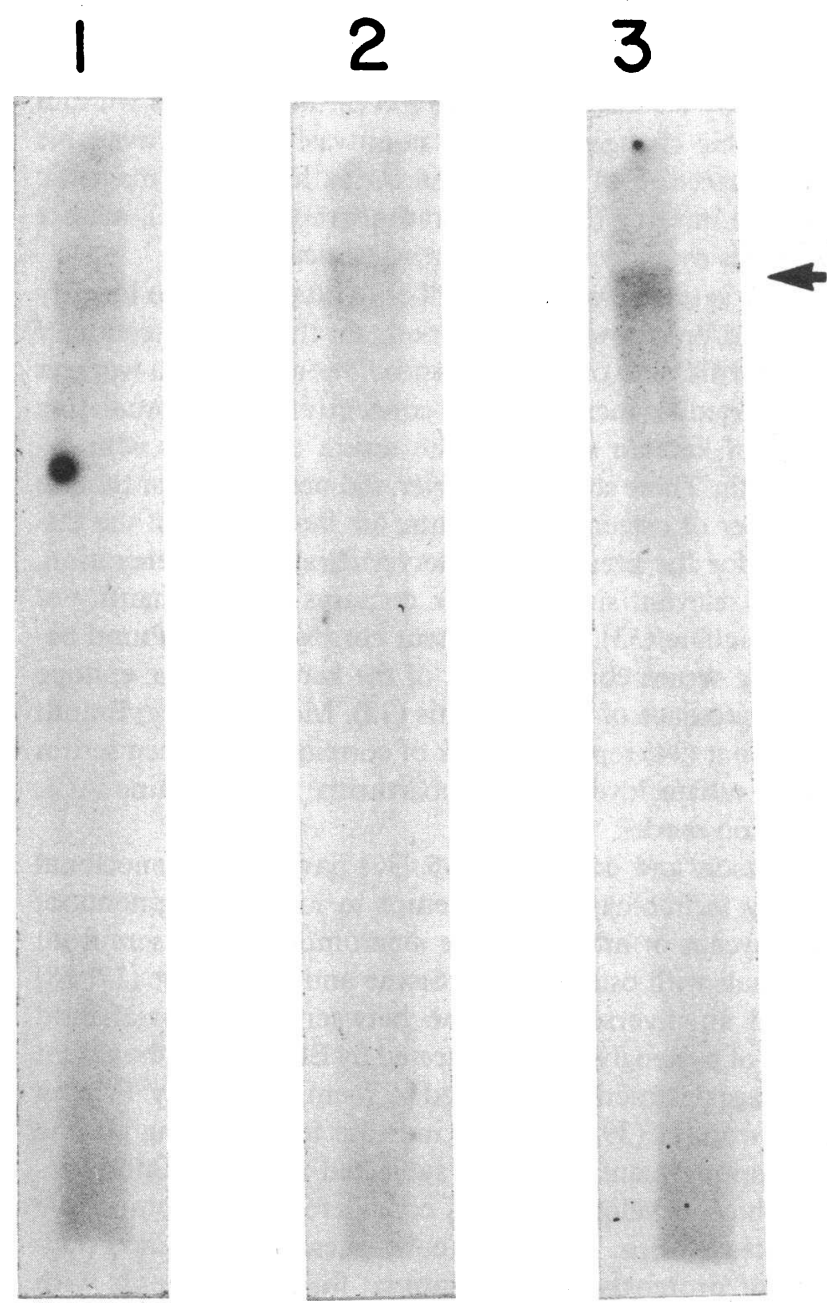

Figure 2. Electrophoretic transfer from $9 \%$ gel to nitrocellulose membrane of serum samples from dog subjected to anterior cruciate ligament transection. The membrane was incubated with the monoclonal antibody, followed by incubation with ${ }^{125}$ I-labeled goat antimouse immunoglobulin antiserum. Lane 1 contains serum obtained at 0 wk (before anterior cruciate ligament transection); 2 contains serum obtained 4 wk postoperatively; and 3 contains serum obtained at the time of sacrifice, $8 \mathrm{wk}$ after surgery. All samples were reduced with 2-mercaptoethanol. Note band at $\sim 116,000$ (arrow), representing the subunit of CMGP, in lane 3.

CMGP obtained by electroelution from a $9 \%$ gel of a bovine cartilage extract (Fife, R. S., and M. Mundy, manuscript in preparation) was used as a control for the reaction of the monoclonal antibody with CMGP (Fig. 3).

4 wk postoperatively a protein band with an apparent molecular weight of 116,000 in $9 \%$ gels was noted in immunolocation studies of reduced serum samples, using the monoclonal antibody, from three of the eight dogs that were negative before surgery (Table I). Samples from the four dogs whose serum contained CMGP before surgery also reacted positively 4 wk after surgery. At sacrifice 8-14 wk after ACL transection, serum from 10 dogs revealed CMGP in transfers of $9 \%$ gels after reduction with 2-mercaptoethanol (Table I and Fig. 2). Serum samples from two dogs (dogs 9 and 12) were negative for CMGP at all time points. No immunoreactive bands were

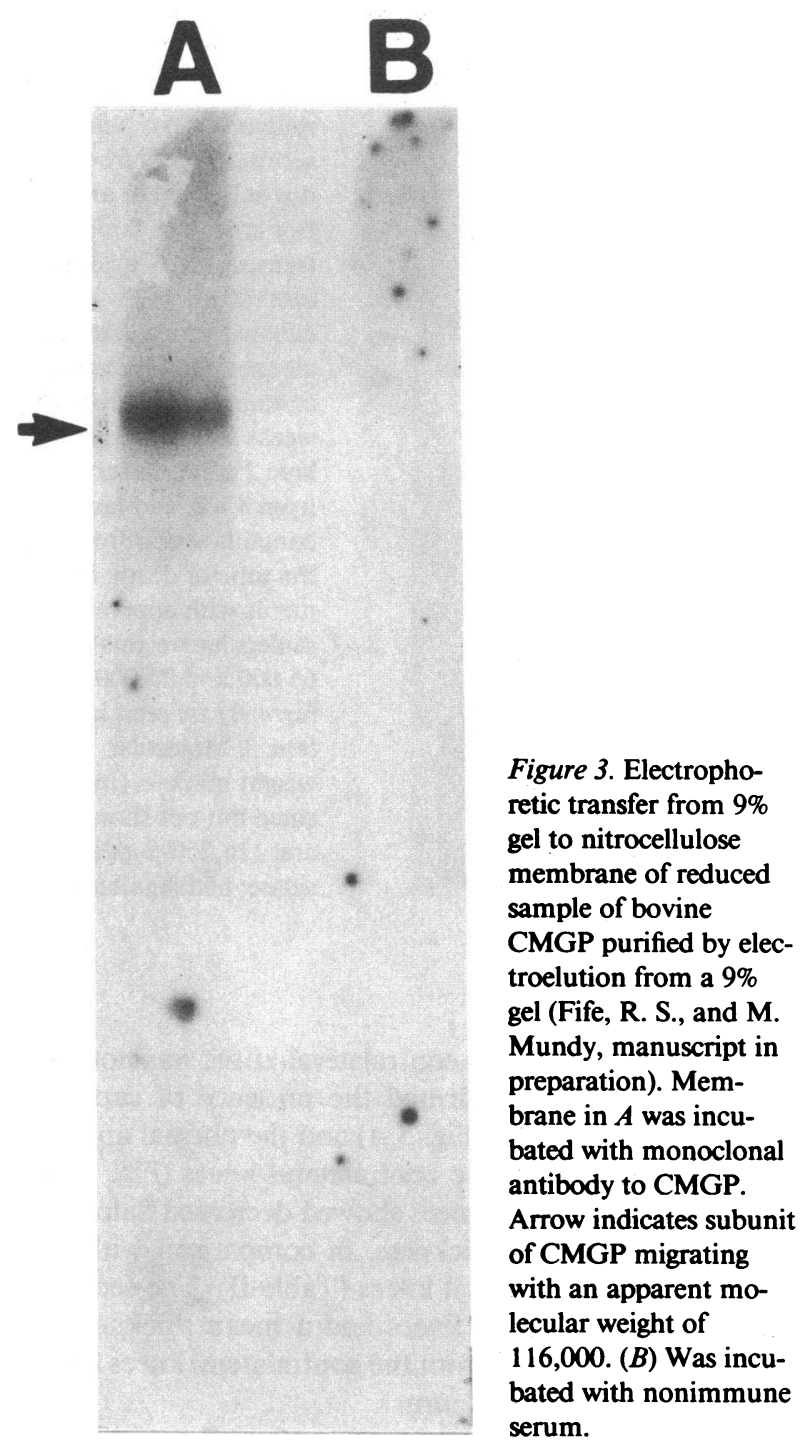

seen when any of the serum samples were incubated with nonimmune serum as a control.

Three dogs demonstrated immunoreactive fragments of CMGP (migrating with apparent molecular weights of 65,000 and 75,000 ) in serum $4 \mathrm{wk}$ after surgery and/or at death, and one of these dogs showed only the fragments and no subunit protein after incubation with the monoclonal antibody (Fig. 4).

Studies of reduced serum samples revealed an identical time course for the appearance of CMGP when examined with the polyclonal antiserum, as compared with the monoclonal antibody, in dogs $1,2,3$, and 7 (Table I). The reaction of the monoclonal antibody and the polyclonal antiserum differed in dogs 4,5 , and 6 before surgery and in dogs 5 and 6 four weeks after surgery (Table I). Serum from dog 4 was negative with the monoclonal antibody at $0 \mathrm{wk}$ but positive with the polyclonal antiserum, while serum samples from dogs 5 and 6 were positive with the monoclonal antibody and negative with the polyclonal antiserum before surgery and $4 \mathrm{wk}$ later.

Cartilage atrophy. In contrast to the osteoarthritis model, gross inspection of the cartilage from the casted knees showed 


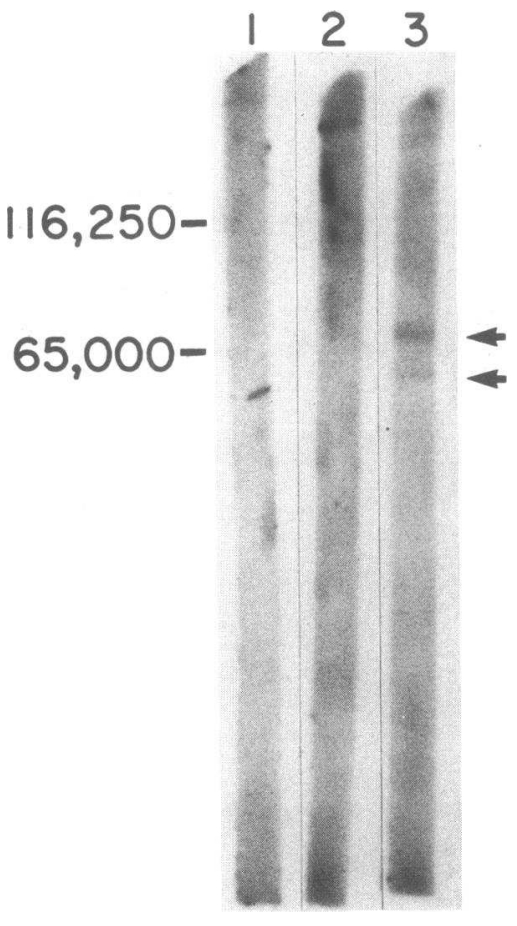

Figure 4. Electrophoretic transfer of reduced serum samples from dog subjected to anterior cruciate ligament transection. Nitrocellulose membrane was incubated with the monoclonal antibody. Lane 1 contains serum from 0 weeks (before surgery), lane 2 contains serum from $4 \mathrm{wk}$, and lane 3 contains serum from the time of death. Fragments with apparent molecular weights of 65,000 and 75,000 (arrows) are seen in lane 3. Molecular weight markers (indicated but not shown) are: $116,250-\beta$-galactosidase; 65,000 -albumin

thinning, while that from the contralateral knees was normal. Histologic examination confirmed the presence of cartilage atrophy in the casted knees (Fig. $5 \mathrm{~A}$ ) and the normal appearance of the cartilage from the contralateral knees (Fig. $5 B$ ). Samples from immobilized knees showed decreased Safranin$O$ staining and decreased thickness, in comparison with the samples from the contralateral knees (Table II). The sections of cartilage from the casted knees had a mean thickness of $0.60 \pm 0.10 \mathrm{~mm}$, while those from the contralateral knees had a mean thickness of $0.87 \pm 0.18 \mathrm{~mm}$.

The mean uronic acid concentration of cartilage from the casted knees was $4.0 \pm 0.1 \%$ dry weight of cartilage, while that of the samples from the uncasted knees was $4.0 \pm 0.2 \%$ (Table II). The mean water content of cartilage from the immobilized knees was $70.5 \pm 3.3 \%$, while that from the contralateral knees was $69.9 \pm 1.9 \%$ (Table II).

Serial samples of serum from dogs with cartilage atrophy contained no material that was immunoreactive with CMGP at any time point (Table II and Fig. 6). Similarly, no specific bands were noted after incubation of the serum samples with nonimmune serum.

Comparison of net glycosaminoglycan synthesis by osteoarthritic cartilage (114 $\pm 27.7 \%$ of control) and atrophic cartilage $(45.3 \pm 7.7 \%$ of control) (reported as percentage of that of the corresponding control knee in Tables I and II) revealed decreased glycosaminoglycan synthesis by the atrophic cartilage.

\section{Discussion}

The diagnosis of osteoarthritis usually depends on a combination of clinical and roentgenographic findings. The latter are not often evident until the disease is relatively far advanced, though radiographic evidence of osteoarthritis can be found in $\sim 80 \%$ of individuals over the age of $55(27,28)$. Although the disease may be recognized arthroscopically in joints without radiographic changes, the only noninvasive means available for the detection of early osteoarthritis have been magnetic resonance imaging (29) and ultrasonography $(30,31)$, neither of which is available for widespread clinical use.

Work is under way in a number of laboratories to identify serum and/or synovial fluid markers for the early detection of osteoarthritis and other arthritides. Thonar and co-workers (32) reported an increase in the concentration of a circulating epitope of keratan sulfate in the serum of patients with osteoarthritis. These studies, however, did not control for the size or number of osteoarthritic joints, for the severity of the disease, or for the presence of intervertebral disc degeneration, which is relevant since the disk contains a large quantity of keratan sulfate (33). No consistent correlation was found between the serum concentration of the keratan sulfate epitope and the presence of osteoarthritis (32). More recently, Brandt and Thonar (34) reported a lack of correlation between serum keratan sulfate levels and osteoarthritis in the canine ACL transection model.

Caterson and colleagues $(35,36)$ have used monoclonal antibody technology in an attempt to identify fragments of proteoglycans or other cartilage macromolecules in sera from individuals with osteoarthritis. Saxne and co-workers $(37,38)$ reported an inverse correlation between the synovial fluid content of proteoglycans, as detected by ELISA, and the extent of cartilage destruction, as judged by roentgenography. Friman and co-workers (39) found an increase in circulating plasma glycosaminoglycans in rabbits subjected to joint immobilization, which developed lesions considered to be compatible with osteoarthritis. Poole and colleagues (40) identified fragments of proteoglycans in synovial fluids of patients with rheumatoid arthritis. Gysen and Franchimont (41) have reported a sensitive radioimmunoassay capable of detecting small amounts of human proteoglycans in serum and synovial fluid.

Morphologic studies in this and other laboratories have shown that canine cartilage is minimally abnormal 4 wk after ACL transection, although net glycosaminoglycan synthesis $(42,43)$ and water content $(43)$ are generally increased. The osteoarthritis which develops in this model is commonly associated with a decrease in the proteoglycan (uronic acid) concentration of the matrix $(9,42,44)$ and a corresponding decrease in Safranin-O staining. Typically, however, in the early stages of this model and, occasionally, even in later stages the uronic acid concentration and Safranin-O staining may be increased $(43,45,46)$, as seen in the present study (Table I). A similar phenomenon can occur in human osteoarthritis (47). This presumably represents deposition and retention in the matrix of large quantities of newly synthesized proteoglycans during a repair attempt by the chondrocyte (48).

It is unknown at present whether CMGP is a marker of cartilage degradation or of cartilage repair in osteoarthritis. The fragmentation of CMGP in serum from several dogs in this study suggests proteolytic degradation. The significant diminution in glycosaminoglycan synthesis by the atrophic cartilage as compared with the osteoarthritic cartilage is consistent with previous studies demonstrating increased synthesis of matrix components by chondrocytes in early osteoarthritis 

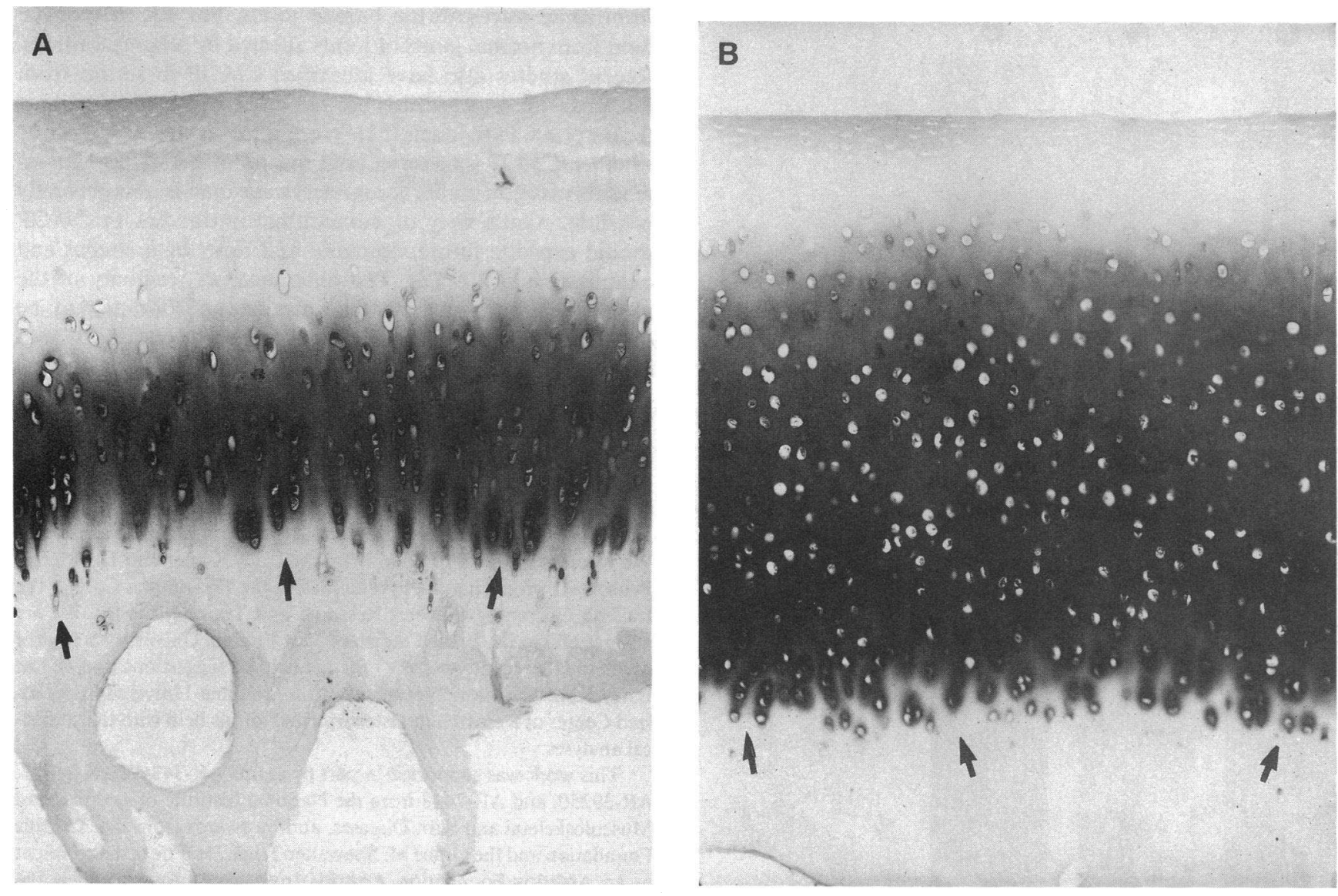

Figure 5. Section of atrophic knee cartilage $(A)$ and contralateral knee cartilage $(B)$ from immobilized dog at sacrifice after 8 wk of casting. Note marked thinning of cartilage and decreased Safranin-O-staining in the sample from the immobilized knee. Cartilage in B is normal. Arrows indicate the tidemark. $(\times 100$.

$(8,43-48)$ and decreased synthesis by chondrocytes in atrophic cartilage $(10,49)$. It is possible that synthesis of CMGP is also increased in early osteoarthritis and is responsible for the egress of the protein from cartilage into serum.

In the present study, we have demonstrated that material immunoreactive with CMGP could be detected in 10 of 12 dogs subjected to ACL transection, but not in serum from 3 dogs with experimental cartilage atrophy (10). The detection of CMGP by monoclonal antibody in the serum of four dogs before limb destabilization may indicate the existence of naturally occurring osteoarthritis in the operated knee or, more likely, in other joints of these animals. Unfortunately, only the knees were examined at death.

Although dogs with sham anterior cruciate ligament transection were not included in this study, we recently found (Fife, R. S., B. L. O’Connor, and K. D. Brandt, unpublished

Table II. Biochemical and Histologic Changes in Cartilage and Presence of CMGP in Serum of Dogs with Cartilage Atrophy Induced by Immobilization in a Cast

\begin{tabular}{|c|c|c|c|c|c|c|c|c|c|c|}
\hline \multirow[b]{3}{*}{ Dog No. } & & & \multicolumn{4}{|c|}{ Compositional analysis of articular cartilage } & & & & \multirow{3}{*}{$\begin{array}{c}\text { Glycosaminoglycan } \\
\text { synthesis } \\
\text { (\% control) }\end{array}$} \\
\hline & \multicolumn{2}{|c|}{$\begin{array}{l}\text { Mean cartilage } \\
\text { thickness (mm) }\end{array}$} & \multicolumn{2}{|c|}{$\begin{array}{l}\text { Water (\% total } \\
\text { weight) }\end{array}$} & \multicolumn{2}{|c|}{$\begin{array}{l}\text { Uronic acid } \\
\text { (\% dry weight) }\end{array}$} & \multicolumn{3}{|c|}{$\begin{array}{l}\text { Serum CMGP, weeks after } \\
\text { application of cast }\end{array}$} & \\
\hline & $\mathrm{CK}^{*}$ & IK & CK & IK & CK & IK & 0 & 4 & Sacrifice & \\
\hline 1 & 1.09 & 0.55 & 67.5 & 66.0 & 4.0 & 3.9 & $-\ddagger$ & - & - & 42 \\
\hline 2 & 0.65 & 0.50 & 70.2 & 71.8 & 4.3 & 4.0 & - & - & - & 56 \\
\hline 3 & 0.86 & 0.74 & 72.1 & 73.8 & 3.8 & 4.2 & - & - & - & 38 \\
\hline
\end{tabular}

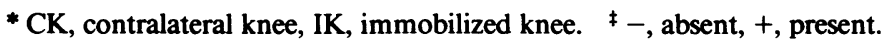



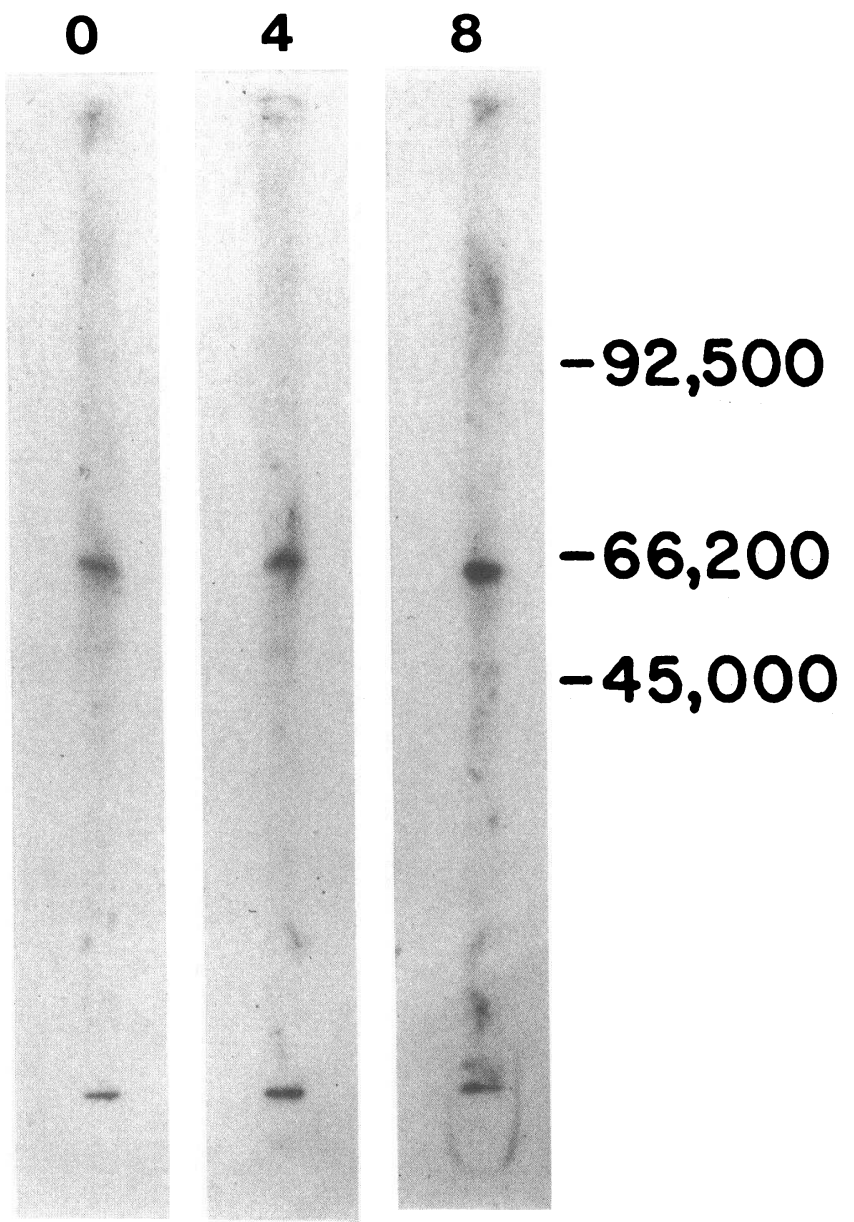

Figure 6. Electrophoretic transfer of serum samples from dog before casting ( $0 \mathrm{wk}$ ) and 4 and $8 \mathrm{wk}$ after casting, examined by immunolocation with specific polyclonal antiserum, followed by incubation with ${ }^{125}$ I-labeled Staphylococcal protein A. All samples were reduced with 2-mercaptoethanol. Note absence of any immunoreactive material migrating with apparent molecular weight of 116,000 representing CMGP (see Figs. 2 and 3). Band at $60-65,000$ is nonspecific and also has been noted sometimes in control serum and after incubation with nonimmune serum. Molecular weight markers (indicated but not shown) are: 92,500-phosphorylase B; 66,200-BSA; 45,000-ovalbumin.

observations) that serum from each of three dogs which underwent sham ligament transection and dorsal root ganglionectomy of L4-S1 as part of a study of neurogenic acceleration of osteoarthritis contained no detectable CMGP 20 wk after the sham procedure. None of these dogs developed osteoarthritis, whereas dogs that undergo the neurosurgical procedure and transection of the cruciate ligament have been shown to develop severe breakdown of the ipsilateral knee (50).

It is possible that our monoclonal antibody might have detected an epitope on CMGP in the serum of the casted dogs, but this seems unlikely because all of the samples were negative using the polyclonal antiserum. At $8 \mathrm{wk}$ no samples from osteoarthritic dogs were negative when tested with the polyclonal antiserum that were positive with the monoclonal antibody.

As indicated earlier, other studies from this laboratory (4) have demonstrated that CMGP is present in synovial fluid from some osteoarthritic human joints, but not in synovial fluid from normal joints or joints affected by other arthritides. Recent studies also have identified CMGP in serum from humans with osteoarthritis but not other forms of arthritis, or from normal individuals (51). Work is under way to determine whether CMGP can serve as a means to detect human osteoarthritis at an earlier (or milder) stage than is now generally possible. Availability of monoclonal antibodies to CMGP should expedite future structural and functional studies and quantitation of CMGP. The differences in reactivity of the monoclonal antibody and the polyclonal antiserum may be due to recognition of slightly different epitopes on CMGP or to differences in binding affinity for CMGP.

\section{Acknowledgments}

We are grateful to Marjorie Albrecht, Malinda Mundy, Kelly King, and Holly Hamilton-Yekinni for their technical assistance and to Donna White and Roberta Fehrman for their secretarial assistance. We would particularly like to thank William Kuster and Dr. Merrill Benson for producing the hybridomas in the Hybridoma Core of the Indiana University Diabetes Research and Training Center. We are also grateful to Dr. Bruce Caterson (West Virginia University School of Medicine, Morgantown, WV) for his helpful suggestions and to Dr. Barry Katz (Director, Biostatistics Core, Indiana University Specialized Center of Research in Osteoarthritis) for his help with the statistical analyses.

This work was supported in part by grants AR-34367, AR-20582, AR-39250, and AR-7448 from the National Institute of Arthritis and Musculoskeletal and Skin Diseases, and by awards from the Arthritis Foundation and the Grace M. Showalter Trust. Dr. Fife is the recipient of an Arthritis Foundation Arthritis Investigator Award and is the Allied Corporation Investigator in Osteoarthritis.

\section{References}

1. Fife, R. S., and K. D. Brandt. 1984. Identification of a high-molecular-weight $(>400,000)$ protein in hyaline cartilage. Biochim. Biophys. Acta. 802:506-514.

2. Fife, R. S. 1985 . Identification of link proteins and a 116,000 dalton matrix protein in canine meniscal cartilage. Arch. Biochem. Biophys. 240:682-688.

3. Nguyen, B. Q., and R. S. Fife. 1986. Vitreous contains a cartilage-related protein. Exp. Eye Res. 43:375-382.

4. Fife, R.S. 1988. Identification of cartilage matrix glycoprotein in synovial fluid in human osteoarthritis. Arthritis Rheum. 31:553-556.

5. Fife, R. S., M. J. Palmoski, and K. D. Brandt. 1986. Metabolism of a cartilage matrix glycoprotein by normal and osteoarthritic canine articular cartilage. Arthritis Rheum. 29:1256-1262.

6. Fife, R. S., G. L. Hook, and K. D. Brandt. 1985. Topographic localization of a 116,000 -dalton protein in cartilage. J. Histochem. Cytochem. 33:127-133.

7. Fife, R. S. 1986. Alterations in a cartilage matrix glycoprotein in canine osteoarthritis. Arthritis Rheum. 29:1493-1500.

8. Palmoski, M. J., R. A. Colyer, and K. D. Brandt. 1980. Marked suppression by salicylate of the augmented proteoglycan synthesis in osteoarthritic cartilage. Arthritis Rheum. 23:83-91.

9. Palmoski, M. J., and K. D. Brandt. 1983. In vivo effect of aspirin on canine osteoarthritic cartilage. Arthritis Rheum. 26:994-1001.

10. Palmoski, M., E. Perricone, and K. D. Brandt. 1979. Development and reversal of a proteoglycan aggregation defect in normal canine knee cartilage after immobilization. Arthritis Rheum. 22:508517.

11. Laemmli, U. K. 1970. Cleavage of structural proteins during the assembly of the head of bacteriophage T4. Nature (Lond.). 227:680-685.

12. Towbin, H., P. Staehelin, and J. Gordon. 1979. Electrophoretic 
transfer of protein from polyacrylamide gels to nitrocellulose sheets: procedure and some applications. Proc. Natl. Acad. Sci. USA. 76:4350-4354.

13. Newhall, W. J., V, B. Batteiger, and R. B. Jones. 1982. Analysis of the human serological response to proteins of Chlamydia trachomatis. Infect. Immun. 38:1181-1189.

14. Johnson, D. A., J. W. Gautsch, J. R. Sportsman, and J. H Elder. 1984. Improved technique utilizing nonfat dry milk for analysis of proteins and nucleic acids transferred to nitrocellulose. Gene Anal. Tech. 1:3-8.

15. Paulsson, M., and D. Heinegard. 1981. Purification and structural characterization of a cartilage matrix protein. Biochem. $J$ 197:367-375.

16. Oegema, T. R., Jr., V. C. Hascall, and D. D. Dziewiatkowski. 1975. Isolation and characterization of proteoglycans from the Swarm rat chondrosarcoma. J. Biol. Chem. 250:6151-6159.

17. Caterson, B., J. R. Baker, D. Levitt, and J. W. Paslay. 1979. Radioimmunoassay of the link proteins associated with bovine nasal cartilage proteoglycan. J. Biol. Chem. 254:9369-9372.

18. Kearney, J. F., A. Radbruch, B. Leisegang, and K. Rajewsky. 1979. A new mouse myeloma cell line that has lost immunoglobulin expression but permits the construction of antibody-secreting hybrid cell lines. J. Immunol. 123:1548-1550.

19. Kohler, G., and C. Milstein. 1975. Continuous cultures of fused cells secreting antibody of predefined specificity. Nature (Lond.). 256:495-497.

20. Hilderbrand, R. L. 1979. ELISA (enzyme-linked immunosorbent assay). In Rapid Diagnosis in Infectious Disease. M. R. Rytel, editor. CRC Press, Boca Raton, FL. 71-88.

21. Rennard, S. I., R. Berg, G. R. Martin, J. M. Foidart, and P. G. Robey. 1980. Enzyme-linked immunoassay (ELISA) for connective tissue components. Anal. Biochem. 104:205-214.

22. Rennard, S. I., K. Kimata, B. Dusemond, H. J. Barrach, J. Wilczek, J. H. Kimura, and V. C. Hascall. 1981. An enzyme-linked immunoassay for the cartilage proteoglycan. Arch. Biochem. Biophys. 107:399-406.

23. Rosenberg, L. 1971. Chemical basis for the histological uses of Safranin-O in the study of articular cartilage. J. Bone Joint Surg. 53A:69-82.

24. Bitter, T., and H. M. Muir. 1962. A modified uronic acid carbazole reaction. Anal. Biochem. 4:330-334.

25. Brandt, K. D., and M. J. Palmoski. 1976. Organization of ground substance in normal and osteoarthritic cartilage. Arthritis Rheum. 19:209-215.

26. Slowman, S. D., and K. D. Brandt. 1986. Composition and glycosaminoglycan metabolism of articular cartilage from habitually loaded and habitually unloaded sites. Arthritis Rheum. 29:88-94.

27. Kellgren, J. H., and J. S. Lawrence. 1958. Osteoarthritis and disk degeneration in an urban population. Ann. Rheum. Dis. 17:388397.

28. Brandt, K. D. 1985. Osteoarthritis: Clinical patterns and pathology. In Textbook of Rheumatology. W. N. Kelley, E. D. Harris, Jr., S. Ruddy, and C. B. Sledge, editors. Vol. II. W. B. Saunders Co., Philadelphia. 1432-1448.

29. Adams, M. E., and D. K. B. Li. 1986. Magnetic resonance imaging of joint lesions. In Articular Cartilage Biochemistry. K. E. Kuettner, R. Schleyerbach, and V. C. Hascall, editors. Raven Press, New York. 331-348.

30. Namey, T. C. 1985. Nuclear medicine, and special radiologic imaging and technique in the diagnosis of rheumatic diseases. In Textbook of Rheumatology. W. N. Kelley, E. D. Harris, Jr., S. Ruddy, and C. B. Sledge, editors. Vol. I. W. B. Saunders Co., Philadelphia. 608-631.

31. Aisen, A. M., W. J. McCune, A. MacGuire, P. L. Carson, T. M. Silver, S. Z. Jafri, and W. Martel. 1984. Sonographic evaluation of the cartilage of the knee. Radiology. 153:781-784.
32. Thonar, E. J.-M. A., M. E. Lenz, G. K. Klintworth, B. Caterson, L. M. Pachman, P. Glickman, R. Katz, J. Huff, and K. E. Kuettner. 1985. Quantification of keratan sulfate in blood as a marker of cartilage catabolism. Arthritis Rheum. 28:1367-1376.

33. Muir, H. M. 1980. The chemistry of the ground substance of joint cartilage. In The Joints and Synovial Fluid. L. Sokoloff, editor. Vol. II. Academic Press, New York. 27-94.

34. Brandt, K. D., and E. J.-M. A. Thonar. 1989. Lack of association between serum keratan sulfate concentrations and cartilage changes of osteoarthritis after transection of the anterior cruciate ligament in the dog. Arthritis Rheum. 32:647-651.

35. Caterson, B., J. E. Christner, J. R. Baker, and J. R. Couchman 1985. Production and characterization of monoclonal antibodies directed against connective tissue proteoglycans. Fed. Proc. 44:386-393.

36. Caterson, B., M. E. Adams, T. Calabro, and R. H. Pearce. 1987. Agarose/acrylamide gel electrophoresis and monoclonal antibody immunolocation as a means of characterizing proteoglycan subpopulations. Trans. 33rd Mtg. Orthop. Res. Soc. 12:60. (Abstr.)

37. Saxne, T., F. A. Wollheim, D. Heinegard, and H. Petterson. 1985. Difference in cartilage proteoglycan level in synovial fluid in early rheumatoid arthritis and reactive arthritis. Lancet. ii:127-128.

38. Saxne, T., D. Heinegard, and F. A. Wollheim. 1986. Therapeutic effects on cartilage metabolism in arthritis as measured by release of proteoglycan structures into the synovial fluid. Ann. Rheum. Dis. 45:491-497.

39. Friman, C., I. Eronen, and T. Videman. 1982. Plasma glycosaminoglycans in experimental osteoarthritis caused by immobilization. J. Rheumatol. 9:292-294.

40. Poole, A. R., N. Roberts, and I. Campbell. 1987. Immunological studies of the degradation of cartilage proteoglycans in vitro compared with in vivo. Trans. 33rd Ann. Mtg. Orthop. Res. Soc. 12:249. (Abstr.)

41. Gysen, P., and P. Franchimont. 1984. Radioimmunoassay of proteoglycans. J. Immunoassay. 5:221-243.

42. Eyre, D. R., C. A. McDevitt, M. E. J. Billingham, and H. Muir 1980. Biosynthesis of collagen and other matrix proteins by articular cartilage in experimental osteoarthrosis. Biochem. J. 188:823-837.

43. McDevitt, C. A., and H. Muir. 1976. Biochemical changes in the cartilage of the knee in experimental and natural osteoarthritis in the dog. J. Bone Joint Surg. 58B:94-101.

44. Sandy, J. D., M. E. Adams, M. E. J. Billingham, and H. Muir. 1984. In vivo and in vitro stimulation of chondrocyte biosynthetic activity in early experimental osteoarthritis. Arthritis Rheum. 27:388397.

45. Brandt, K. D., N. B. Wurster, and G. Lust. 1986. Fibronectin in degenerating cartilage: Relationship to chondrocyte cloning. Trans. 32nd Ann. Mtg. Orthop. Res. Soc. 11:255. (Abstr.)

46. Vignon, E., M. Arlot, D. Hartmann, B. Moyen, and G. Ville. 1983. Hypertrophic repair of articular cartilage in experimental osteoarthritis. Ann. Rheum. Dis. 42:82-88.

47. Thompson, R. C., Jr., and T. R. Oegema, Jr. 1979. Metabolic activity of articular cartilage in osteoarthritis. An in vitro study. J. Bone Joint Surg. 61A:407-416.

48. Mankin, H. J., and K. D. Brandt. 1984. Biochemistry and metabolism of cartilage in osteoarthritis. In Osteoarthritis: Diagnosis and Management. R. W. Moskowitz, D. S. Howell, V. M. Goldberg, and H. J. Mankin, editors. W. B. Saunders Co., Philadelphia. 43-79.

49. Palmoski, M. J., and K. D. Brandt. 1981. Running inhibits the reversal of atrophic changes in canine knee cartilage after removal of a leg cast. Arthritis Rheum. 24:1329-1337.

50. O'Connor, B. L., M. J. Palmoski, and K. D. Brandt. 1985. Neurogenic acceleration of degenerative joint lesions. J. Bone Joint Surg. 47A:562-572.

51. Fife, R. S., M. H. Doran, M. R. Sherman, M. Mundy, and S. DeAtley. 1988. Presence of cartilage matrix glycoprotein (CMGP) in serum in human osteoarthritis. Clin. Res 36:532a. (Abstr.) 